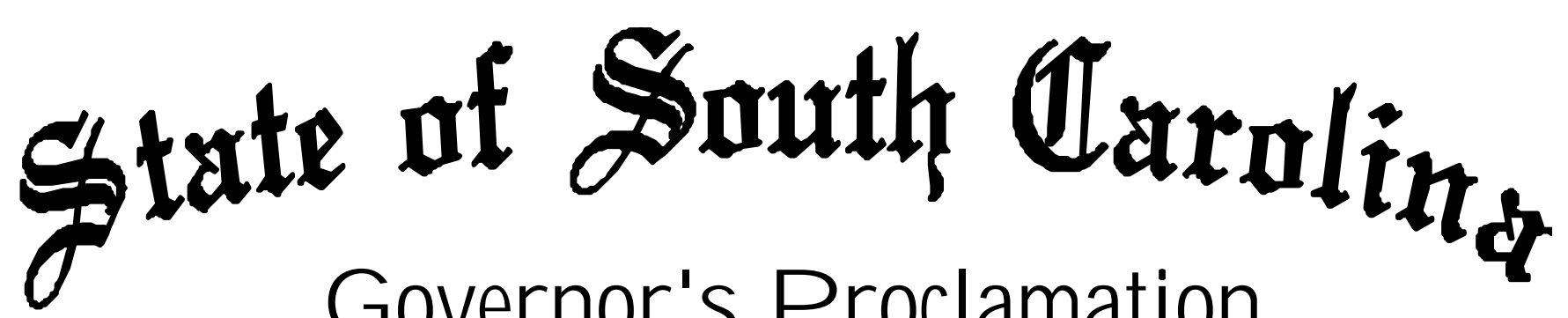 \\ G overnor's P roclamation
}

WHEREAS, the crime of domestic violence violates an individual's privacy, dignity, security, and humanity through the systematic use of physical, emotional, sexual, psychological, and economic control and/or abuse; and

WHEREAS, South Carolina ranks $3^{\text {rd }}$ in the nation for the number of women killed by abusive partners, with nearly 15,000 women and children receiving services from domestic violence centers last year alone; and

WHEREAS, the effects of domestic violence on children are devastating and can cause lifelong problems due to emotional and/or physical trauma; and

WHEREAS, Domestic Violence Awareness Month calls attention to the importance of working together to assure a life free from harm for all South Carolinians.

NOW, THEREFORE, I, Mark Sanford, Governor of the Great State of South Carolina, do hereby proclaim October 2003 as

\section{DOMESTIC VIOLENCE AWARENESS MONTH}

throughout the state and encourage all South Carolinians to join together in recommitting ourselves to eliminating domestic violence, reaching out to its victims, and letting them know that help is available.
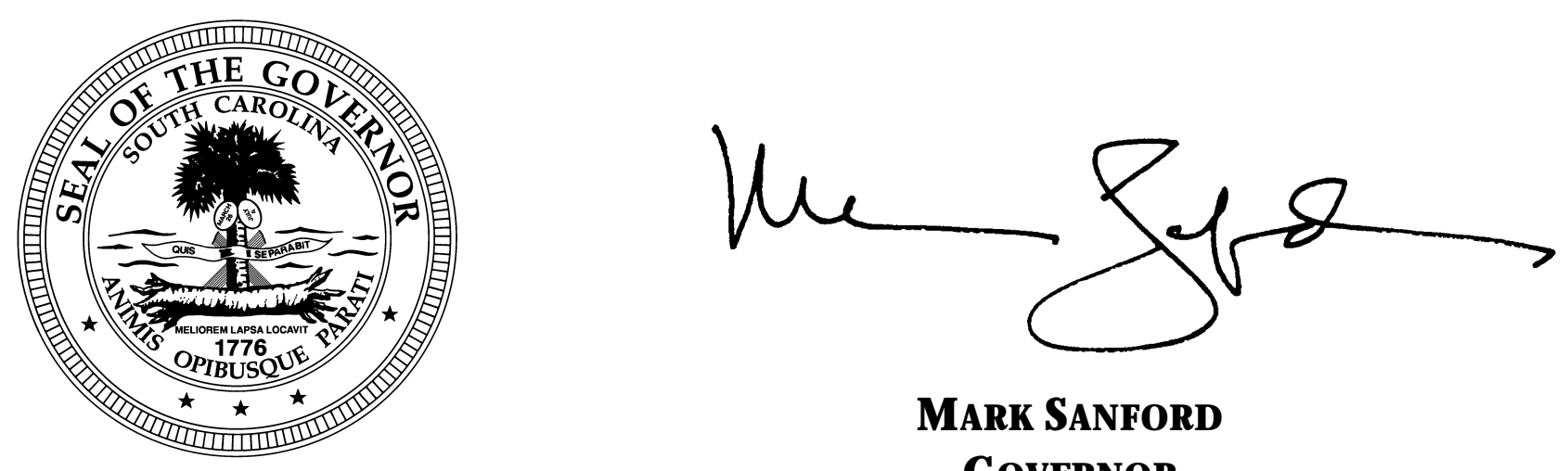

MARK SANFORD

GOVERNOR

State of South Carolina 